\title{
Ecotropic virus integration-1 and calreticulin as novel prognostic markers in triple-negative breast cancer: A retrospective cohort study
}

\author{
DONGNING HE ${ }^{1,2}$, LEI WU ${ }^{1}$, XIAOXI LI ${ }^{1}$, XIAODAN LIU ${ }^{1}$, PING MA $^{1 *}$ and YOUHONG JUANG ${ }^{1}$ \\ ${ }^{1}$ Molecular Oncology Laboratory of Cancer Research Institute, The First Affiliated Hospital of China Medical University, \\ Shenyang, Liaoning 110001; ${ }^{2}$ Department of Oncology, The First Affiliated Hospital of Jinzhou Medical University, \\ Jinzhou, Liaoning 121001, P.R. China
}

Received October 6, 2018; Accepted May 9, 2019

DOI: $10.3892 / \mathrm{ol} .2019 .10472$

\begin{abstract}
Triple-negative breast cancer (TNBC) is an aggressive form of breast cancer, for which no specific targete $\mathrm{d}$ therapy is currently available. The present study aimed to examine the associations of ecotropic virus integration site 1 (EVI-1) and calreticulin (CRT) with other clinicopathological variables and the prognosis of patients with TNBC. The present retrospective cohort study reviewed the medical records of patients with TNBC treated in the Affiliated Hospitals of Jinzhou Medical University between January 2010 and June 2015. The protein expression levels of EVI-1 and CRT in tumor samples obtained from the patients were examined by immunohistochemical analysis. Univariate and multivariate regression analyses were used to identify associations between clinical characteristics and disease-free survival (DFS) or overall survival (OS). Kaplan-Meier analysis was performed to observe the survival condition (DFS/OS) according to EVI-1 and CRT expression. A total of 88 TNBC patients were included in the present study. Tumor tissues in $52(59.1 \%)$ patients were EVI-1 positive, and tumor tissues in 64 (72.7\%) patients were CRT-positive, and these rates were significantly higher compared with those in the corresponding paracancerous tissues $(\mathrm{P}<0.05)$. Multivariate analysis revealed that EVI-1 and CRT expression levels were independent variables associated with OS and DFS, and high expression of both CRT and EVI-1 was significantly associated with decreased OS and DFS compared with the other subgroups (low EVI-1/low CRT expression,
\end{abstract}

Correspondence to: Dr Youhong Juang, Molecular Oncology Laboratory of Cancer Research Institute, The First Affiliated Hospital of China Medical University, 155 Nanjing Street, Shenyang, Liaoning 110001, P.R. China

E-mail: jiangyouhong2000@aliyun.com

"Deceased

Key words: ecotropic virus integration-1, calreticulin, prognosis, triple-negative breast cancer, tumor tissue low EVI-1/high CRT expression and high EVI-1/low CRT expression) of patients with TNBC. EVI-1 and CRT expression in TNBC was significantly correlated with poor outcome. Evaluation of the EVI-1 and CRT status may provide insight into prognosis prediction for patients with TNBC.

\section{Introduction}

Breast cancer accounts for $\sim 25 \%$ of all cancer cases and $\sim 15 \%$ of cancer-associated mortalities in females worldwide (1). Triple-negative breast cancer (TNBC) refers to breast cancer that is negative for the expression of the estrogen receptor (ER), progesterone receptor (PR) and hormone epidermal growth factor receptor 2 (HER2) (2). TNBC accounts for $15-20 \%$ of all breast cancer pathological types (2). Treatment for breast cancer includes surgery, chemotherapy, radiation, endocrine and targeted therapy (3). As TNBC tumor tissue lacks expression of ER, PR and HER-2, patients with TNBC cannot benefit from endocrine therapy or targeted therapy against HER-2, unlike patients with other subtypes of breast cancer (4-7). Therefore, TNBC is a biologically aggressive subtype of breast cancer and has a poor prognosis $(8,9)$. There is currently no specific targeted therapy for TNBC (10).

The ecotropic virus integration site 1 (EVI-1) protein is an oncogenic dual domain zinc finger transcription factor that was first identified to be abnormally expressed in myeloid tumors in mice (11). EVI-1 has since been revealed to be highly expressed in several solid tumors, including pancreatic, colorectal and prostate cancer, glioblastoma, infratentorial ependymoma and hepatocellular carcinoma, and to negatively correlate with prognosis (12-18). A common EVI-1 polymorphism (rs6774494 A $>$ G) targeted by microRNA (miR)-206/133b was suggested to predict adverse outcomes in patients with postmenopausal breast carcinoma (19). In breast cancer, EVI-1 expression was associated with poor outcome in patients with ER-negative breast cancer $(20,21)$. Calreticulin (CRT) is a multifunctional calcium-binding molecular chaperone. It serves an important role in promoting tumor cell proliferation, metastasis and adhesion, as well as inducing apoptosis resistance (22). CRT is highly expressed in malignant tumors, including breast cancer, and is associated with a poor prognosis (21-27). 
Several predictive biomarkers in TNBC, including the epidermal growth factor receptor (EGFR), androgen receptor and the adhesion molecules CD24 and CD44, have been investigated in recent years (28-31). To the best of the authors' knowledge, the prognostic value of the expression levels of CRT and EVI-1 in TNBC is unknown. Therefore, the present study investigated the associations between the expression levels of EVI-1 and CRT and the clinical characteristics, disease-free survival (DFS) and overall survival (OS) of patients with TNBC.

\section{Materials and methods}

Study population. The current retrospective cohort study was approved by the Ethical Review Committee of the First Affiliated Hospital of Jinzhou Medical University (no. 2018-0006). All patients provided written informed consent prior to enrollment.

The medical records of The First Affiliated Hospital and the Third Affiliated Hospital of Jinzhou Medical University between January 2010 and June 2015 were reviewed, and patients who met the following eligibility criteria were included in the current study: i) $\geq 18$ years; ii) received surgical resection following breast cancer diagnosis in the aforementioned time period; iii) defined as TNBC following immunohistochemical analysis (negative for ER, PR and HER-2 expression); and iv) positive for EGFR expression. The exclusion criteria were as follows: i) Male patients; ii) treatment with neo-adjuvant chemotherapy, radiotherapy or endocrine therapy prior to resection; iii) confirmed distant metastasis; and iv) refusal to provide written consent.

Patient clinical information, including age, tumor size, TNM stage according to the 7th American Joint Committee on Cancer staging system (32), lymph node metastasis, histological type and treatment received, were obtained from the medical records. A paraffin-embedded specimen of TNBC tumor tissue and a matched paracancerous tissue specimen (defined as tissues beyond $5 \mathrm{~cm}$ from the edge of the tumor tissue) from each patient. All patients with TNBC were followed-up until August 2016.

Immunohistochemical analysis. TNBC tissue samples were processed and subjected to immunohistochemical staining as follows. Tissue specimens were fixed with $10 \%$ formalin and kept away from light at room temperature. Paraffin-embedded tissue sections $(4 \mu \mathrm{m})$ were deparaffinized in xylene, rehydrated with a gradient of ethanol and washed in distilled water. A pressure cooker was used to perform the antigen retrieval step using citrate buffer at $108^{\circ} \mathrm{C}$ for $1-2$ min. A $3 \%$ hydrogen peroxide/methanol solution was used to block the endogenous peroxidase activity for $15 \mathrm{~min}$ at room temperature. Non-specific antibody binding was subsequently blocked by incubation with $1 \%$ diluted normal horse serum (Beijing Solarbio Science \& Technology Co., Ltd.) for $30 \mathrm{~min}$ at room temperature. The sections were incubated at room temperature for 60 min with antibodies against EVI-1 (ab-28457, 1:800; Abcam) and CRT (ab4, 1:2,000; Abcam). The sections were visualized using the SP-9001 kit and DAB kit (Rabbits SP kit; cat. no. SP-9001; OriGene Technologies, Inc.) following the manufacturer's instructions and counterstained with hematoxylin at room temperature for $1 \mathrm{~min}$. Sections incubated with PBS and without a primary antibody served as a negative control. Five high-power fields of view (magnification, $\mathrm{x} 400$ ) were randomly selected in each section using a light microscope.

EVI-1 and CRT immunoreactivity was evaluated independently by CSX and YJJ using a manual histopathology scoring method (33). For evaluation of EVI-1 and CRT staining, light yellow to brown particles in the cytoplasm and/or nucleus were defined as positive. A semi-quantitative scoring was used to judge the overall score based on tissue staining intensity and the percentage of positive cells according to the standard reported by Wang et al (34). Image-pro plus software (version 6.0; Media Cybernetics, Inc.) was used to conduct image analysis. Three sections were selected from each group (cancerous tissue and paracancerous tissue) according to the random number method, and five visual fields at $\mathrm{x} 400$ magnification were randomly chosen from each section for measurement of the average optical density of positive staining (integrated optical density (IOD)/area). Quantitative results are presented in Fig. 1, which represents the difference of IOD among the different groups. The staining intensity was characterized as 0 points for no coloring, 1 point for weak staining, 2 points for medium staining and 3 points for strong staining $(19,35,36)$. The percentage of positive cells was categorized as follows: 0 points for no positive cells, 1 point for $\leq 25 \%$ positive area, 2 points for $26-50 \%$ positive area, 3 points for $51-75 \%$ positive area and 4 points for $>75 \%$ positive area. To obtain the overall score, the aforementioned two scores were multiplied, and a result of 0-4 was defined as low expression (negative) and 6-12 as high expression (positive).

Statistical analysis. A Chi-square test was performed to assess the associations between EVI-1 and CRT expression and various clinicopathological variables. The Spearman's correlation test was used to determine if the expression levels of EVI-1 and CRT correlated with TNBC. Comparison among multiple groups were performed by one-way analysis of variance followed by the least-significant difference test. The main outcomes of the current study were OS and DFS. DFS referred to the period from the date of primary surgery to the date of diagnosis of distant or local recurrence, and OS was defined as the period from the date of primary surgery to the date of mortality from any cause. The Kaplan-Meier method to evaluate the median DFS and OS times and the log-rank test was used to test the significance of differences in DFS and OS. Multivariable analysis of predictors of DFS and OS was performed using the Cox proportional hazards regression model. $\mathrm{P}<0.05$ was considered to indicate a statistically significant difference. Statistical analysis was performed using SPSS statistical software (version 17; SPSS, Inc, Chicago, IL, USA).

\section{Results}

Patient information. A total of 88 patients with TNBC who met the eligibility criteria were included in the final analysis. The patient characteristics are presented in Table I. The mean age of the patients was 54 years (range, 30-77 years). The median follow-up time was 43.5 months (range, 

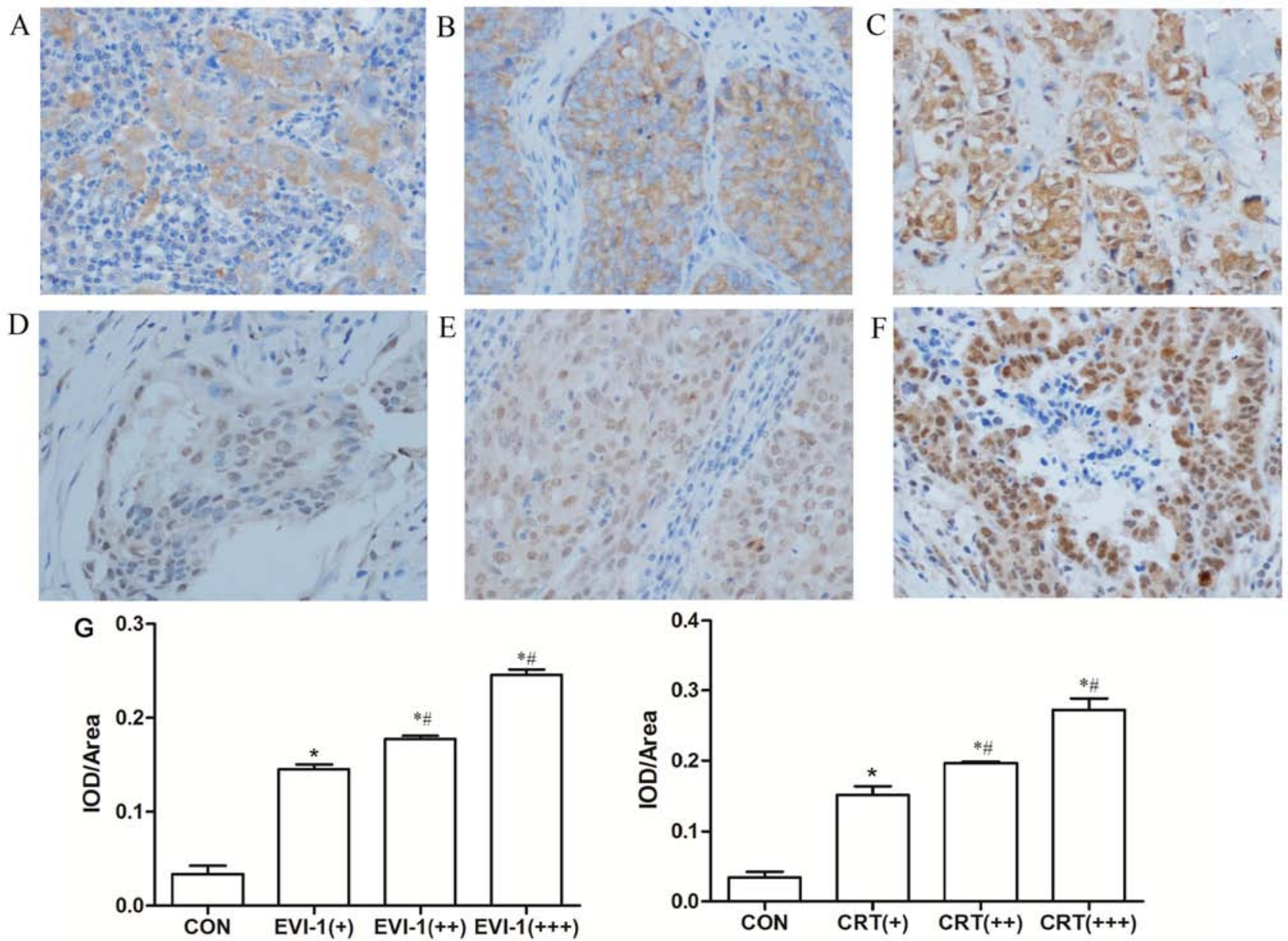

Figure 1. Immunohistochemical staining for EVI-1and CRT in triple-negative breast cancer tumor samples and paracancerous tissue. (A-C) EVI-1 staining from (A) weak (+), (B) medium (++) to (C) strong (+++). (D-F) CRT staining from (D) weak (+), (E) medium (++) to (F) strong (+++). (G) EV1-1 and CRT expression in paracancerous tissue as a control. Quantitative results for this staining are presented in the histogram, and the data represent the IOD/integrated optic density/area (within the EVI-1 or CRT positive group and compared with the negative control group). Significant differences were determined by the one-way analysis of variance followed by the least-significant difference test. Magnification, $\mathrm{x} 400$. ${ }^{*} \mathrm{P}<0.05$ vs. negative control; ${ }^{~} \mathrm{P}<0.05$ vs. EVI-1(+). EVI-1, ecotropic virus integration site 1; CRT, calreticulin; IOD, integrated optic density; CON, control.

12-75 months). No patient data were lost during the follow-up. At the end of the study, 62.5\% (55/88) of the patients had experienced local/distant recurrence, and $51.13 \%(45 / 88)$ had succumbed.

EVI-1 and CRT expression in TNBC and paracancerous tissues. Among the 88 patients with TNBC, 59.1\% exhibited high expression levels of EVI-1. EVI-1 immunostaining was mainly localized in the cytoplasm, but staining was also present in the nuclei of tumor cells (Fig. 1). High expression of CRT was observed in $72.7 \%$ of the patients, and its expression was localized in the nucleus and cytoplasm (Fig. 1). Staining for EVI-1 and CRT revealed low expression levels in all adjacent normal tissues. Statistically significant differences in the expression of EVI-1 and CRT were observed between the TNBC tumor tissues and adjacent normal tissues $(\mathrm{P}<0.05$; Table II). The positive rates of EVI-1 and CRT staining in TNBC tissues were significantly higher than those in adjacent healthy tissues $(\mathrm{P}<0.05)$.

EVI-1 and CRT expression in TNBC. Among the 88 cases of TNBC, 44 revealed high expression levels of both EVI-1 and
CRT, and 16 cases had low expression of both. The Spearman's correlation test demonstrated that the expression levels of EVI-1 and CRT were significantly positively correlated with TNBC $\left(\mathrm{r}^{2}=0.321 ; \mathrm{P}=0.002\right.$; data not shown).

Association of EVI-1 and CRT expression levels with other clinicopathological variables. The expression levels of EVI-1 and CRT in TNBC was associated with clinicopathological variables (Table III). High expression of EVI-1 was closely associated with the histopathological type, cancer-associated thrombosis, lymph node metastasis, pathological stage and elevated Ki-67 expression $(\mathrm{P}<0.05)$. Chi-square analysis revealed that the expression of CRT was closely associated with age and elevated Ki-67 expression $(\mathrm{P}<0.05)$. Younger age and higher Ki-67 expression were associated with increased expression of CRT.

Clinicopathological variables associated with poor prognosis in TNBC. COX risk regression models revealed that age, BMI, Ki-67 expression, EVI-1 expression and CRT expression were independent risk factors for a poor prognosis of TNBC (Table IV). 
Table I. Patient clinicopathological characteristics $(\mathrm{N}=88)$.

\begin{tabular}{|c|c|c|}
\hline Characteristic & Category & $\mathrm{N}(\%)$ \\
\hline \multirow[t]{3}{*}{ Age (years) } & $30-45$ & $21(23.9)$ \\
\hline & $46-61$ & $48(54.5)$ \\
\hline & $62-77$ & $19(21.6)$ \\
\hline Sex & Female & $88(100)$ \\
\hline \multirow[t]{4}{*}{ Body mass index $\left(\mathrm{kg} / \mathrm{m}^{2}\right)$} & $\leq 18.49$ & $2(2.3)$ \\
\hline & $18.5-24.99$ & $49(55.7)$ \\
\hline & $25-27.99$ & $23(26.1)$ \\
\hline & $28-32$ & $14(15.9)$ \\
\hline \multirow[t]{3}{*}{ Histopathological type } & Invasive ductal/lobular carcinoma & $76(86.4)$ \\
\hline & Apocrine carcinoma & $5(5.7)$ \\
\hline & Others & $7(8.0)$ \\
\hline \multirow[t]{3}{*}{ T-stage ${ }^{a}$} & $\mathrm{~T} 1$ & $28(31.8)$ \\
\hline & $\mathrm{T} 2$ & $58(65.9)$ \\
\hline & T3-T4 & $2(2.3)$ \\
\hline \multirow[t]{3}{*}{ Number of lymph nodes with metastasis } & 0 & $53(60.2)$ \\
\hline & $\leq 4$ & $25(28.4)$ \\
\hline & $>4$ & $10(11.4)$ \\
\hline \multirow[t]{2}{*}{ Cancer-associated thrombosis } & Yes & $72(81.8)$ \\
\hline & No & $16(18.2)$ \\
\hline \multirow[t]{3}{*}{ Histological differentiation grade ${ }^{b}$} & Low/moderate & $35(39.8)$ \\
\hline & High & $38(43.2)$ \\
\hline & Moderate/high & $15(17.0)$ \\
\hline \multirow[t]{3}{*}{ Pathological stage $^{\mathrm{a}}$} & $\mathrm{I}$ & $30(34.1)$ \\
\hline & II & $41(46.6)$ \\
\hline & III & $17(19.3)$ \\
\hline \multirow[t]{2}{*}{ Ki-67 staining } & Low $(\leq 14 \%)$ & $9(10.2)$ \\
\hline & High $(>14 \%)$ & $79(89.8)$ \\
\hline \multirow[t]{2}{*}{ p53 staining } & Negative & $40(45.5)$ \\
\hline & Positive & $48(54.5)$ \\
\hline Therapy following surgery & Similar standard treatment & $88(100)$ \\
\hline
\end{tabular}

${ }^{\mathrm{a}}$ According to the 7 th American Joint Committee on Cancer staging system (32). ${ }^{\mathrm{b}}$ According to the WHO classification of breast tumors (2012) (41).

Table II. EVI-1 and CRT expression in TNBC tissues and paracancerous tissues $(\mathrm{n}=88)$.

\begin{tabular}{|c|c|c|c|c|c|c|c|}
\hline \multirow[b]{2}{*}{ Tissue } & \multirow[b]{2}{*}{$\mathrm{N}$} & \multicolumn{2}{|c|}{$\begin{array}{l}\text { Status of EVI-1 protein } \\
\text { expression, } \mathrm{n}(\%)\end{array}$} & \multirow[b]{2}{*}{ P-value } & \multicolumn{2}{|c|}{$\begin{array}{c}\text { Status of CRT expression, } \\
\mathrm{n}(\%)\end{array}$} & \multirow[b]{2}{*}{$\mathrm{P}$-value } \\
\hline & & High & Low & & High & Low & \\
\hline TNBC & 88 & $52(59.1)$ & $36(40.9)$ & $0.003^{\mathrm{a}}$ & $64(72.7)$ & $24(27.3)$ & $0.003^{\mathrm{a}}$ \\
\hline Adjacent normal & 88 & $10(11.4)$ & $78(88.6)$ & & 0 & $88(100)$ & \\
\hline
\end{tabular}

${ }^{\text {a }}<<0.05$. EVI-1, ecotropic virus integration-1; CRT, calreticulin; TNBC, triple-negative breast cancer.

EVI-1/CRT expression and prognosis of patients with TNBC. The survival curves revealed that the OS (mean \pm standard deviation) for patients with a high expression level of EVI-1 was significantly lower compared with patients with a low expression level $(36.79 \pm 1.67$ months vs. 58.11 \pm 3.42 months;
$\mathrm{P}<0.001$; Fig. 2). Similar results were obtained for the DFS (24.62 \pm 1.72 months vs. 45.57 \pm 3.09 months; $\mathrm{P}<0.001$; Fig. 2).

The OS of patients with high CRT expression was significantly lower compared with that of patients with low 
Table III. Correlations between EVI-1 and CRT expression in cancer tissues and clinicopathological variables in patients with triple-negative breast cancer $(n=88)$.

\begin{tabular}{|c|c|c|c|c|c|c|c|}
\hline \multirow[b]{2}{*}{ Variable } & \multirow[b]{2}{*}{ Category } & \multicolumn{2}{|c|}{ EVI-1 } & \multirow[b]{2}{*}{ P-value } & \multicolumn{2}{|c|}{ CRT } & \multirow[b]{2}{*}{ P-value } \\
\hline & & Negative & Positive & & Negative & Positive & \\
\hline \multirow[t]{3}{*}{ Age (years) } & $30-45$ & 11 & 10 & $0.168^{\mathrm{a}}$ & 1 & 20 & $0.020^{\mathrm{a}}$ \\
\hline & $46-61$ & 16 & 32 & & 15 & 33 & \\
\hline & $62-77$ & 10 & 9 & & 8 & 11 & \\
\hline \multirow[t]{4}{*}{ BMI $\left(\mathrm{kg} / \mathrm{m}^{2}\right)$} & $<18.5$ & 1 & 1 & 0.692 & 1 & 1 & 0.427 \\
\hline & $18.5-24.99$ & 22 & 27 & & 16 & 33 & \\
\hline & $25-28$ & 7 & 16 & & 5 & 18 & \\
\hline & $28-32$ & 6 & 8 & & 2 & 12 & \\
\hline \multirow[t]{3}{*}{ Histopathological type } & $\begin{array}{l}\text { Invasive ductal/lobular } \\
\text { carcinoma }\end{array}$ & 29 & 47 & $0.031^{\mathrm{a}}$ & 19 & 57 & 0.481 \\
\hline & Apocrine carcinoma & 1 & 4 & & 2 & 3 & \\
\hline & Others & 6 & 1 & & 3 & 4 & \\
\hline \multirow{3}{*}{$\begin{array}{l}\text { Histological differentiation } \\
\text { grade }^{\text {b }}\end{array}$} & Low/moderate & 13 & 22 & 0.251 & 9 & 26 & 0.952 \\
\hline & High & 19 & 19 & & 11 & 27 & \\
\hline & Moderate/high & 4 & 11 & & 4 & 11 & \\
\hline \multirow{2}{*}{$\begin{array}{l}\text { Cancer-associated } \\
\text { thrombosis }\end{array}$} & No & 34 & 38 & $0.012^{\mathrm{a}}$ & 21 & 51 & 0.397 \\
\hline & Yes & 2 & 14 & & 3 & 13 & \\
\hline \multirow[t]{3}{*}{ T-stage ${ }^{c}$} & $\mathrm{~T} 1$ & 13 & 15 & 0.728 & 11 & 17 & 0.183 \\
\hline & $\mathrm{T} 2$ & 22 & 36 & & 13 & 45 & \\
\hline & T3-T4 & 1 & 1 & & 1 & 1 & \\
\hline \multirow{3}{*}{$\begin{array}{l}\text { Number of lymph-node } \\
\text { metastases }\end{array}$} & 0 & 27 & 26 & $0.030^{\mathrm{a}}$ & 16 & 37 & 0.419 \\
\hline & $\leq 4$ & 8 & 17 & & 7 & 18 & \\
\hline & $>4$ & 1 & 9 & & 1 & 9 & \\
\hline \multirow[t]{3}{*}{ Pathological stage ${ }^{c}$} & I & 15 & 15 & $0.024^{\mathrm{a}}$ & 11 & 19 & 0.183 \\
\hline & II & 19 & 22 & & 11 & 30 & \\
\hline & III & 2 & 15 & & 2 & 15 & \\
\hline \multirow[t]{2}{*}{ p53 } & Negative & 17 & 23 & 0.830 & 12 & 28 & 0.637 \\
\hline & Positive & 19 & 29 & & 12 & 36 & \\
\hline \multirow[t]{2}{*}{ Ki-67 } & $\leq 14 \%$ & 7 & 2 & $0.029^{\mathrm{a}}$ & 7 & 2 & $<0.001^{\mathrm{a}}$ \\
\hline & $>14 \%$ & 29 & 50 & & 17 & 62 & \\
\hline
\end{tabular}

${ }^{\mathrm{a}} \mathrm{P}<0.05$. EVI-1, ecotropic virus integration-1; CRT, calreticulin. ${ }^{\mathrm{b}}$ According to WHO classification of breast tumors (2012) (41). ${ }^{\mathrm{c} A c c o r d i n g}$ to the 7th American Joint Committee on Cancer staging system (32).

CRT expression (42.76 \pm 2.54 months vs. 50.44 \pm 3.12 months; $\mathrm{P}=0.036$; Fig. 3). However, the level of CRT expression did not result in a significant difference in PFS (high expression, $31.35 \pm 2.44$ months vs. low expression, $35.00 \pm 2.88$ months; $\mathrm{P}=0.323$; Fig. 3).

Combination of EVI-1 and CRT expression as a prognostic biomarker in TNBC. The present study further explored whether combining EVI-1 and CRT expression statuses may be used as a prognostic biomarker for patients with TNBC. The patients were sub-categorized into four groups according to EVI-1 and CRT expression status: i) Low EVI-1/low CRT expression ( $\mathrm{N}=16)$; ii) low EVI-1/high CRT expression $(\mathrm{n}=20)$; iii) high EVI-1/low CRT expression $(\mathrm{N}=8)$, and iv) high EVI-1/high CRT expression (N=44). Among the four groups, Kaplan-Meier analyses revealed significant differences in DFS
$(\mathrm{P}<0.001)$ and OS $(\mathrm{P}<0.001)$. Additionally, this difference was greatest between the high EVI-1/high CRT group and all other groups (Fig. 4). Subsequent analysis revealed that patients in the high EVI-1/high CRT group $(\mathrm{N}=44)$ had significantly reduced DFS $(\mathrm{P}<0.001$, log-rank test $)$ and OS $(\mathrm{P}<0.001$, log-rank test $)$ compared with patients in all other groups ( $\mathrm{N}=44$; Fig. 4$)$.

\section{Discussion}

The current retrospective cohort study evaluated the effects of EVI-1 and CRT expression on the clinicopathological features and prognosis of patients with TNBC. The expression levels of EVI-1 and CRT in TNBC and paracancerous tissues were analyzed. EVI-1 and CRT expression was low or absent in paracancerous tissues and increased in TNBC tissues, which is consistent with previous studies $(21,24)$. No 
Table IV. Multivariate analysis of predictive factors for disease-free survival and overall survival in patients with triple-negative breast cancer $(n=88)$.

A, Overall survival

\begin{tabular}{|c|c|c|c|}
\hline Variable & Odds ratio & $95 \%$ confidence interval & P-value \\
\hline Age (46-61 years) & 4.175 & $1.06-16.44$ & $0.041^{\mathrm{a}}$ \\
\hline Age (62-77 years) & 4.369 & $1.43-13.25$ & $0.010^{\mathrm{a}}$ \\
\hline BMI $\left(18.5-24.99 \mathrm{~kg} / \mathrm{m}^{2}\right)$ & 55.793 & $2.739-1136.489$ & $0.009^{\mathrm{a}}$ \\
\hline Pathological stage (II) & 0.236 & $0.059-0.950$ & $0.042^{\mathrm{a}}$ \\
\hline CRT & 1.506 & $0.516-4.394$ & 0.453 \\
\hline EVI-1 & 0.114 & $0.034-0.380$ & $<0.001^{\mathrm{a}}$ \\
\hline p53 & 2.688 & $1.153-6.266$ & $0.022^{\mathrm{a}}$ \\
\hline Ki-67 & 0.066 & $0.007-0.578$ & $0.014^{\mathrm{a}}$ \\
\hline B, Disease-free survival & Odds ratio & $95 \%$ confidence interval & P-value \\
\hline BMI $\left(18.5-24.99 \mathrm{~kg} / \mathrm{m}^{2}\right)$ & 76.399 & $4.347-1342.653$ & $0.003^{\mathrm{a}}$ \\
\hline Pathological stage (II) & 0.219 & $0.051-0.937$ & $0.041^{\mathrm{a}}$ \\
\hline Pathological stage (III) & 0.297 & $0.089-0.996$ & $0.049^{\mathrm{a}}$ \\
\hline CRT & 3.667 & $1.255-10.715$ & $0.018^{\mathrm{a}}$ \\
\hline EVI-1 & 0.097 & $0.027-0.344$ & $<0.001^{\mathrm{a}}$ \\
\hline p53 & 1.978 & $0.881-4.443$ & $0.098^{\mathrm{a}}$ \\
\hline $\mathrm{Ki}-67$ & 0.064 & $0.007-0.571$ & $0.014^{\mathrm{a}}$ \\
\hline
\end{tabular}

${ }^{\mathrm{a}}<0.05$. EVI-1, ecotropic virus integration-1; CRT, calreticulin; BMI, body mass index.
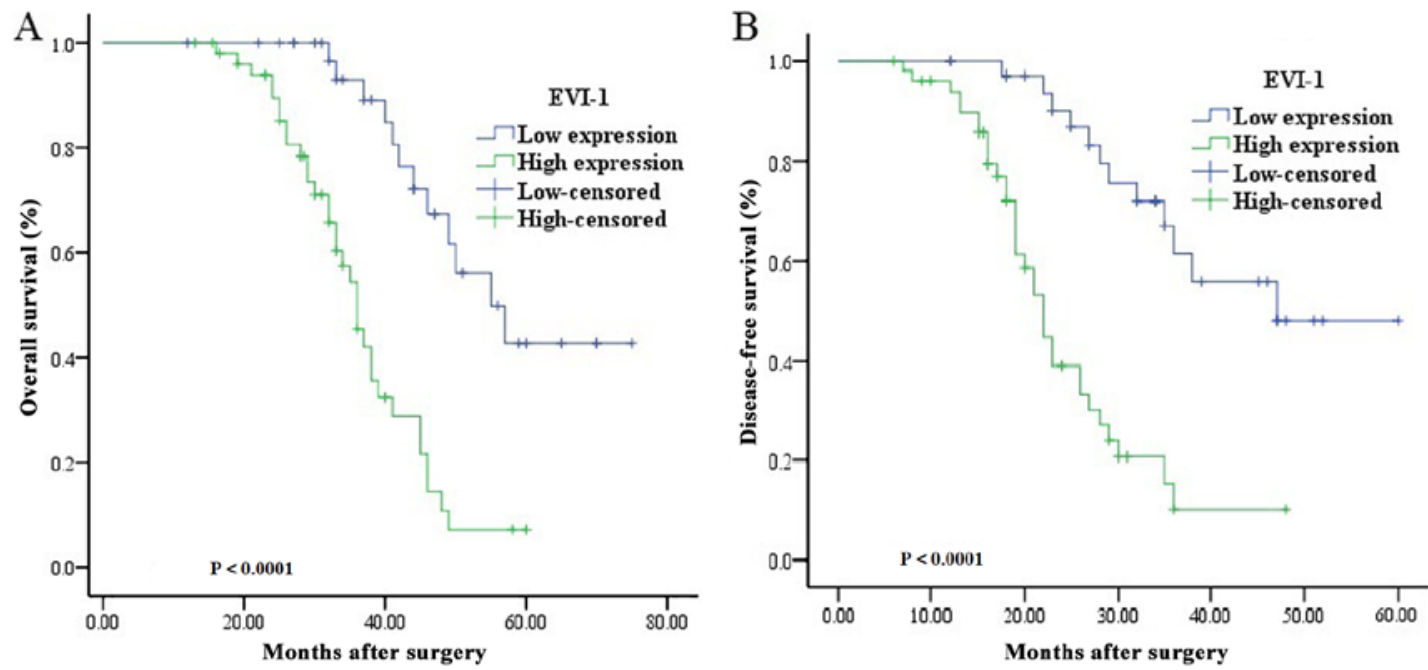

Figure 2. Kaplan-Meier survival curves revealed that patients with triple-negative breast cancer with a high EVI-1 expression level had significantly reduced (A) overall survival and (B) and disease-free survival compared with patients with a low EVI-1 expression level. The data were censored using maximum likelihood estimation. EVI-1, ecotropic virus integration site 1.

association between EVI-1 expression in TNBC tissues and age, BMI, histological grade, tumor size and p53 expression was observed. However, EVI-1 expression was significantly associated with pathological type, presence of vascular tumor embolus, lymph node metastasis, pathological stage and a hyperproliferative Ki-67 index $(\mathrm{P}<0.05)$. The expression of CRT was closely associated with age and Ki-67 expression.
Younger age and higher Ki-67 expression were associated with increased expression of CRT.

As the TNBC cell proliferation activity is increased with elevated expression of $\mathrm{Ki}-67$, the degree of malignancy of TNBC is also increased (37). The results of the present study suggested that the prognosis of patients with TNBC with low EVI-1 expression is improved. Wang et al (14) revealed that 

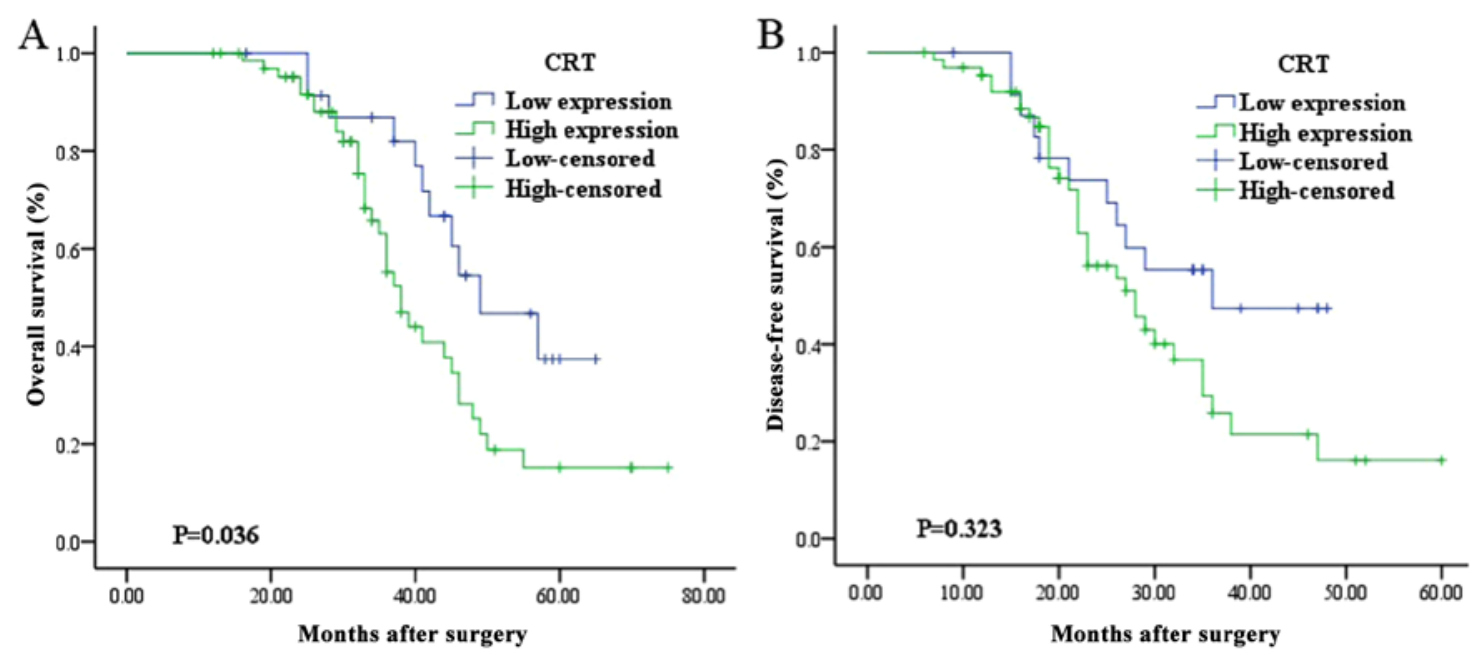

Figure 3. Kaplan-Meier survival curves revealed that patients with triple-negative breast cancer with high a CRT expression level had (A) significantly reduced overall survival but (B) statistically similar disease-free survival compared with patients with a low CRT expression level. CRT, calreticulin.
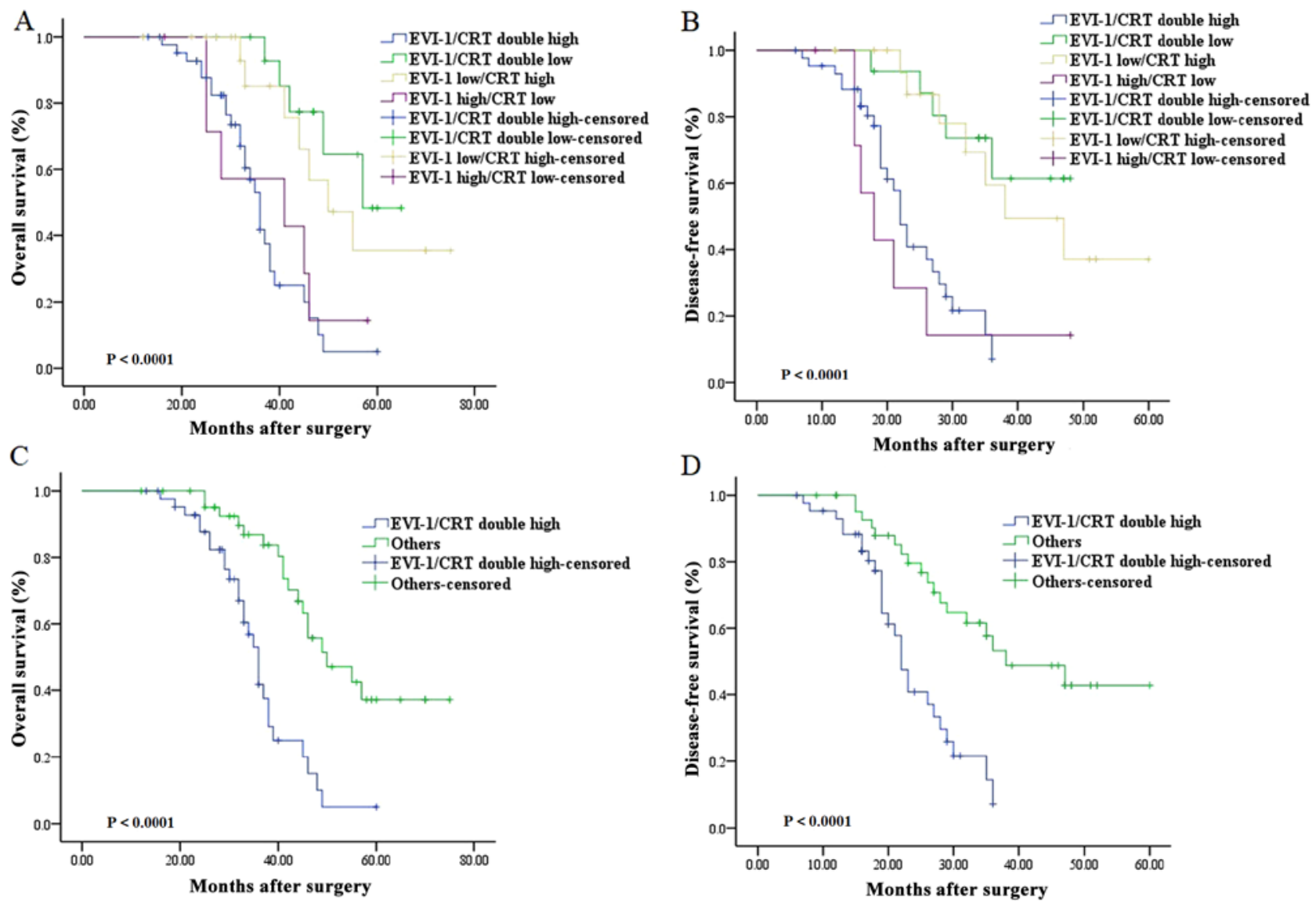

Figure 4. Combination of EVI-1 and CRT expression as a prognostic biological marker. Kaplan-Meier survival curves illustrated that high expression of both EVI-1 and CRT was significantly associated with reduced OS (A) and DFS (B) in patients with TNBC; moreover, TNBC patients with high CRT/high EVI-1 expression had significantly reduced OS (C) and DFS (D) compared with patients in all other groups.

increased expression of EVI-1 is associated with the proliferation of ER and HER-2 negative breast cancer cells, providing a theoretical basis for the current study. The present study revealed that the increased expression of EVI-1 and CRT was associated with an increase in Ki-67 expression, suggesting that EVI-1 and CRT in TNBC tissues may be closely associated with the proliferation of cancer cells. Therefore, it may be speculated that EVI-1 and CRT may be related to invasion and metastasis of cancer cells, thereby affecting patient PFS and OS. Chen et al (38) demonstrated that the increased expression of CRT in gastric cancer was positively correlated with vascular invasion and lymph node metastasis and was associated with poor prognosis. The overexpression of CRT promoted proliferation of pancreatic cancer cells in vitro, whereas knockdown 
of CRT inhibited the proliferation of pancreatic cancer cells (25). CRT is considered to inhibit downstream signaling in the MAPK and p53 signaling pathways (39). However, the mechanisms underlying the effect of EVI-1 expression on the prognosis of patients with TNBC remains unclear. One hypothesis is that EVI-1 may promote the activation of the $\mathrm{PI} 3 \mathrm{~K} / \mathrm{AKT}$ signaling pathway, antagonize the transforming growth factor- $\beta$-signaling pathway, and regulate long-chain non-coding RNA to promote tumor cell proliferation.

The increase expression of EVI-1 and CRT may lead to increased proliferation, invasion and metastasis of TNBC, which in turn affects the PFS and OS of patients with TNBC. By combining the CRT status and EVI-1 status for predicting prognosis in TNBC, the present study demonstrated that patients with high expression of both EVI-1 and CRT had significantly decreased OS and DFS compared with the patients in the other subgroups. Quan et al (35) revealed that the level of miR-206 expression in breast cancer tissue was significantly higher compared with that in adjacent tissues, and that the 3-year survival rate of patients with high miR-206 expression was decreased compared with patients with low miR-206 expression. Our previous studies suggested that miR-206 negatively regulated the expression of transcription factor EVI-1 (40), which indicates that EVI-1 may regulate its expression and have an impact on biological behaviors of tumor cells through specific miRNAs. In addition, recent studies revealed that low expression of suppressor of cytokine signaling 1 and high expression of DNA polymerase $\Delta 1$, catalytic subunit are associated with the occurrence and development of breast cancer and may have prognostic value in breast cancer $(29,30)$. Therefore, testing for both EVI-1 and CRT may be useful to evaluate the prognosis of patients with breast cancer and prevent recurrence. In addition, the identification of novel biomarkers may aid clinical practice and improve patient outcomes.

The present study had a number of limitations. Cases with missing data were excluded from the final analysis, potentially leading to information bias. The effect of therapy on patient outcome was not assessed as all the patients included in the current study received a similar standard treatment strategy. The small sample size limited the statistical power to some degree and more cases are required for future analysis. In conclusion, EVI-1 and CRT may serve important roles in the progression of TNBC. The detection of the expression levels of EVI-1 and CRT may aid the diagnosis of TNBC and serve as a prognosis indicator for patients with TNBC.

\section{Acknowledgements}

Not applicable.

\section{Funding}

The present study was supported by the National Natural Science Foundation of China (grant no. 81372812).

\section{Availability of data and materials}

The datasets used and/or analyzed during the current study are available from the corresponding author on reasonable request.

\section{Authors' contributions}

DNH designed the study, conducted the literature search and patient data collection, appraised all potential studies and wrote and revised the draft manuscript and subsequent manuscripts. LW revised the draft manuscript, data analysis, and subsequent manuscripts. XXL and XDL assisted with the presentation of findings and assisted with drafting and revising the manuscript. XXL collected and followed up the cases. XDL analyzed and interpreted the experimental data. PM and YHJ conceived and designed the study, assisted with searches, appraised relevant studies, and assisted with drafting and revising the manuscript. All authors read and approved the final manuscript.

\section{Ethics approval and consent to participate}

The current retrospective study was approved by The Ethical Review Committee of the First Affiliated Hospital of Jinzhou Medical University (no. 2018-0006). All participants provided written informed consent prior to enrolment.

\section{Patient consent for publication}

Not applicable.

\section{Competing interests}

The authors declare that they have no competing interests.

\section{References}

1. Torre LA, Bray F, Siegel RL, Ferlay J, Lortet-Tieulent J and Jemal A: Global cancer statistics, 2012. CA Cancer J Clin 65: 87-108, 2015.

2. Beiki O, Hall P, Ekbom A and Moradi T: Breast cancer incidence and case fatality among 4.7 million women in relation to social and ethnic background: A population-based cohort study. Breast cancer Res 14: R5, 2012.

3. Gradishar WJ, Anderson BO, Balassanian R, Blair SL, Burstein HJ, Cyr A, Elias AD, Farrar WB, Forero A, Giordano SH, et al: Breast cancer version 2.2015. J Natl Compr Canc Netw 13: 448-475, 2015.

4. Foulkes WD, Smith IE and Reis-Filho JS: Triple-negative breast cancer. N Engl J Med 363: 1938-1948, 2010.

5. Carey LA: Directed therapy of subtypes of triple-negative breast cancer. Oncologist 16 (Suppl 1): S71-S78, 2011.

6. Irvin WJ Jr and Carey LA: What is triple-negative breast cancer? Eur J Cancer 44: 2799-2805, 2008.

7. Adamo V, Ricciardi GR, De Placido S, Colucci G, Conte P, Giuffrida D, Gebbia N, Masci G, Cognetti F, Dondi D and Venturini M: Management and treatment of triple-negative breast cancer patients from the NEMESI study: An Italian experience. Eur J Cancer 48: 642-647, 2012.

8. Bianchini G, Balko JM, Mayer IA, Sanders ME and Gianni L: Triple-negative breast cancer: Challenges and opportunities of a heterogeneous disease. Nat Rev Clin Oncol 13: 674-690, 2016.

9. Hudis CA and Gianni L: Triple-negative breast cancer: An unmet medical need. Oncologist 16 (Suppl 1): S1-S11, 2011.

10. Hon JD, Singh B, Sahin A, Du G, Wang J, Wang VY, Deng FM, Zhang DY, Monaco ME and Lee P: Breast cancer molecular subtypes: From TNBC to QNBC. Am J Cancer Res 6: 1864-1872, 2016.

11. Buonamici S, Chakraborty S, Senyuk V and Nucifora G: The role of EVI1 in normal and leukemic cells. Blood Cells Mol Dis 31: 206-212, 2003

12. Tanaka M, Suzuki HI, Shibahara J, Kunita A, Isagawa T, Yoshimi A, Kurokawa M, Miyazono K, Aburatani H, Ishikawa $S$ and Fukayama M: EVI1 oncogene promotes KRAS pathway through suppression of microRNA-96 in pancreatic carcinogenesis. Oncogene 33: 2454-2463, 2014. 
13. Deng X, Cao Y, Liu Y, Li F, Sambandam K, Rajaraman S, Perkins AS, Fields AP, Hellmich MR, Townsend CM Jr, et al: Overexpression of Evi-1 oncoprotein represses TGF- $\beta$ signaling in colorectal cancer. Mol Carcinog 52: 255-264, 2013.

14. Wang H, Schaefer T, Konantz M, Braun M, Varga Z, Paczulla AM, Reich S, Jacob F, Perner S, Moch H, et al: Prominent oncogenic roles of EVI1 in breast carcinoma. Cancer Res 77: 2148-2160, 2017

15. Hou A, Zhao L, Zhao F, Wang W, Niu J, Li B, Zhou Z and Zhu D Expression of MECOM is associated with unfavorable prognosis in glioblastoma multiforme. Onco Targets Ther 9: 315-320, 2016.

16. Koos B, Bender S, Witt H, Mertsch S, Felsberg J, Beschorner R, Korshunov A, Riesmeier B, Pfister S, Paulus W and Hasselblatt M: The transcription factor evi-1 is overexpressed, promotes proliferation, and is prognostically unfavorable in infratentorial ependymomas. Clin Cancer Res 17: 3631-3637, 2011.

17. Queisser A, Hagedorn S, Wang H, Schaefer T, Konantz M, Alavi S, Deng M, Vogel W, von Mässenhausen A, Kristiansen G, et al: Ecotropic viral integration site 1, a novel oncogene in prostate cancer. Oncogene 36: 1573-1584, 2017.

18. Yasui K, Konishi C, Gen Y, Endo M, Dohi O, Tomie A, Kitaichi T, Yamada N, Iwai N, Nishikawa T, et al: EVI1, a target gene for amplification at $3 \mathrm{q} 26$, antagonizes transforming growth factor- $\beta$-mediated growth inhibition in hepatocellular carcinoma. Cancer Sci 106: 929-937, 2015

19. Wang TY, Huang YP and Ma P: Correlations of common polymorphism of EVI-1 gene targeted by miRNA-206/133b with the pathogenesis of breast cancer. Tumour Biol 35: 9255-9262, 2014

20. Patel JB, Appaiah HN, Burnett RM, Bhat-Nakshatri P, Wang G, Mehta R, Badve S, Thomson MJ, Hammond S, Steeg P, et al: Control of EVI-1 oncogene expression in metastatic breast cancer cells through microRNA miR-22. Oncogene 30: 1290-1301, 2011.

21. Brooks DJ, Woodward S, Thompson FH, Dos Santos B Russell M, Yang JM, Guan XY, Trent J, Alberts DS and Taetle R: Expression of the zinc finger gene EVI-1 in ovarian and other cancers. Br J Cancer 74: 1518-1525, 1996.

22. Lu YC, Chen CN, Wang B, Hsu WM, Chen ST, Chang KJ, Chang CC and Lee $\mathrm{H}$ : Changes in tumor growth and metastatic capacities of J82 human bladder cancer cells suppressed by down-regulation of calreticulin expression. Am J Pathol 179: 1425-1433, 2011.

23. Lwin ZM, Guo C, Salim A, Yip GW, Chew FT, Nan J, Thike AA, Tan PH and Bay BH: Clinicopathological significance of calreticulin in breast invasive ductal carcinoma. Mod Pathol 23: 1559-1566, 2010

24. Erić-Nikolić A, Milovanović Z, Sánchez D, Pekáriková A, Dzodić R, Matić IZ, Tučková L, Jevrić M, Buta M, Rašković S and Juranić Z: Overexpression of calreticulin in malignant and benign breast tumors: Relationship with humoral immunity. Oncology 82: 48-55, 2012.

25. Sheng W, Chen C, Dong M, Zhou J, Liu Q, Dong Q and Li F: Overexpression of calreticulin contributes to the development and progression of pancreatic cancer. J Cell Physiol 229: 887-897, 2014.

26. Chiang WF, Hwang TZ, Hour TC, Wang LH, Chiu CC, Chen HR, Wu YJ, Wang CC, Wang LF, Chien CY, et al: Calreticulin, an endoplasmic reticulum-resident protein, is highly expressed and essential for cell proliferation and migration in oral squamous cell carcinoma. Oral Oncol 49: 534-541, 2013.

27. Peng RQ, Chen YB, Ding Y, Zhang R, Zhang X, Yu XJ, Zhou ZW, Zeng YX and Zhang XS: Expression of calreticulin is associated with infiltration of T-cells in stage IIIB colon cancer. World J Gastroenterol 16: 2428-2434, 2010.
28. Kallel I, Rebai M, Khabir A and Rebaï A: What common biomarkers characterize a triple-negative profile in breast cancer? Pathol Biol (Paris) 63: 224-229, 2015.

29. Ali AM, Ansari JAK, El-Aziz NMA, Abozeed WN, Warith AMA, Alsaleh K and Nabholtz JM: Triple negative breast cancer: A tale of two decades. Anticancer Agents Med Chem 17: 491-499, 2017.

30. Wu N, Zhang J, Zhao J, Mu K, Zhang J, Jin Z, Yu J and Liu J: Precision medicine based on tumorigenic signaling pathways for triple-negative breast cancer. Oncol Lett 16: 4984-4996, 2018.

31. Israel BB, Tilghman SL, Parker-Lemieux K and Payton-Stewart F: Phytochemicals: Current strategies for treating breast cancer. Oncol Lett 15: 7471-7478, 2018.

32. Edge SB and Compton CC: The American Joint Committee on Cancer: The 7th edition of the AJCC cancer staging manual and the future of TNM. Ann Surg Oncol 17: 1471-1474, 2010.

33. Aeffner F, Wilson K, Martin NT, Black JC, Hendriks CL, Bolon B, Rudmann DG, Gianani R, Koegler SR, Krueger J and Young GD: The gold standard paradox in digital image analysis: Manual versus automated scoring as ground truth. Arch Pathol Lab Med 141: 1267-1275, 2017.

34. Wang CJ, Zhou ZG, Holmqvist A, Zhang H, Li Y, Adell G and Sun XF: Survivin expression quantified by Image Pro-Plus compared with visual assessment. Appl Immunohistochem Mol Morphol 17: 530-535, 2009.

35. Quan Y, Huang X and Quan X: Expression of miRNA-206 and miRNA-145 in breast cancer and correlation with prognosis. Oncol Lett 16: 6638-6642, 2018

36. Lv Y, Song G and Li P: Correlation of SOCS-1 gene with onset and prognosis of breast cancer. Oncol Lett 16: 383-387, 2018.

37. Synnestvedt M, Borgen E, Russnes HG, Kumar NT, Schlichting E, Giercksky KE, Kåresen R, Nesland JM and Naume B: Combined analysis of vascular invasion, grade, HER 2 and Ki67 expression identifies early breast cancer patients with questionable benefit of systemic adjuvant therapy. Acta Oncol 52: 91-101, 2013.

38. Chen CN, Chang CC, Su TE, Hsu WM, Jeng YM, Ho MC, Hsieh FJ, Lee PH, Kuo ML, Lee H and Chang KJ: Identification of calreticulin as a prognosis marker and angiogenic regulator in human gastric cancer. Ann Surg Oncol 16: 524-533, 2009.

39. Zamanian M, Qader Hamadneh LA, Veerakumarasivam A, Abdul Rahman S, Shohaimi S and Rosli R: Calreticulin mediates an invasive breast cancer phenotype through the transcriptional dysregulation of p53 and MAPK pathways. Cancer Cell Int 16: 56, 2016.

40. Meng L, Wang TY, Li XX and Ma P: Effects of miR-206/miR-1 on breast cancer stem cell proliferation and the mechanism. J China Med Univ 44: 394-399, 2015

41. Frank GA, Danilova NV, Andreeva IuIu and Nefedova NA WHO classification of tumors of the breast, 2012. Arkh Patol 75: 53-63, 2013 (In Russian).

This work is licensed under a Creative Commons Attribution-NonCommercial-NoDerivatives 4.0 International (CC BY-NC-ND 4.0) License. 